\title{
TeamECR - Treino da Equipa na Emergência Cardiorrespiratória: a Portuguese in-hospital low-dose high-frequency training program.
}

Nelson Santos ${ }^{1,2}$, Paulo Freitas ${ }^{3}$, Maria Luísa Aguiar Camara ${ }^{4}$, Zita Simões ${ }^{1}$, Ricardo Costa ${ }^{1}$, Hélio Jesus ${ }^{1}$, Juan Pozo ${ }^{1}$, Andreia Fernandes ${ }^{1}$

1 - ICU RN at Hospital Prof. Dr. Fernando Fonseca EPE, Amadora, Portugal; 2 - E-mail:

nffsantos@gmail.com; 3 - ICU MD Director at Hospital Prof. Dr. Fernando Fonseca EPE, Amadora,

Portugal; 4 - Chief Nurse at Hospital Prof. Dr. Fernando Fonseca EPE, Amadora, Portugal

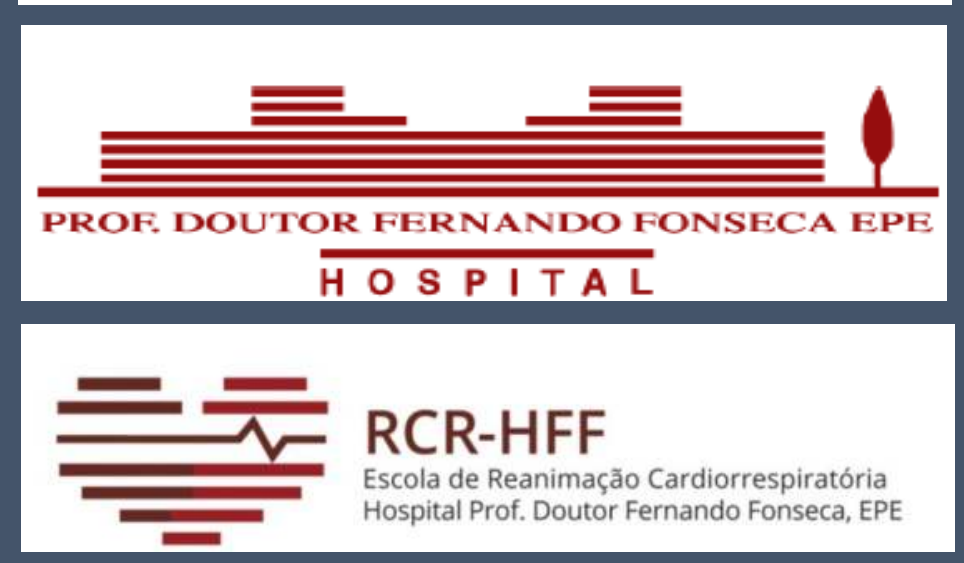

INTRODUCTION: Healthcare providers (HP) resuscitation team training will highly influence in-hospital cardiac arrest (IHCA) outcome. ALS courses don't meet the need of HP to train specificities of their working context.

AIM: To verify if low-dose high-frequency training increases team efficiency at IHCA.

METHODS: This is an observational study in which ICU teams were evaluated during an IHCA simulation. A semiannual 2-hour training program with 4 simulated scenarios was developed from May2012 to Nov-2013 at ICU, which enabled the elements for manipulation of airway adjuncts, crash-car, defibrillator monitor procedures, and also for leadership, closed-loop communication, code management and guidelines adherence. We've standardized a team approach model with 5 members. A record sheet was used for team evaluation during simulations. After $1^{\text {st }}$ training, 3 simulations were carried out, the $4^{\text {th }}$ simulation was evaluated to assess team's performance in relation to leadership and management, equipment handling and guidelines adherence

\section{RESULTS:}
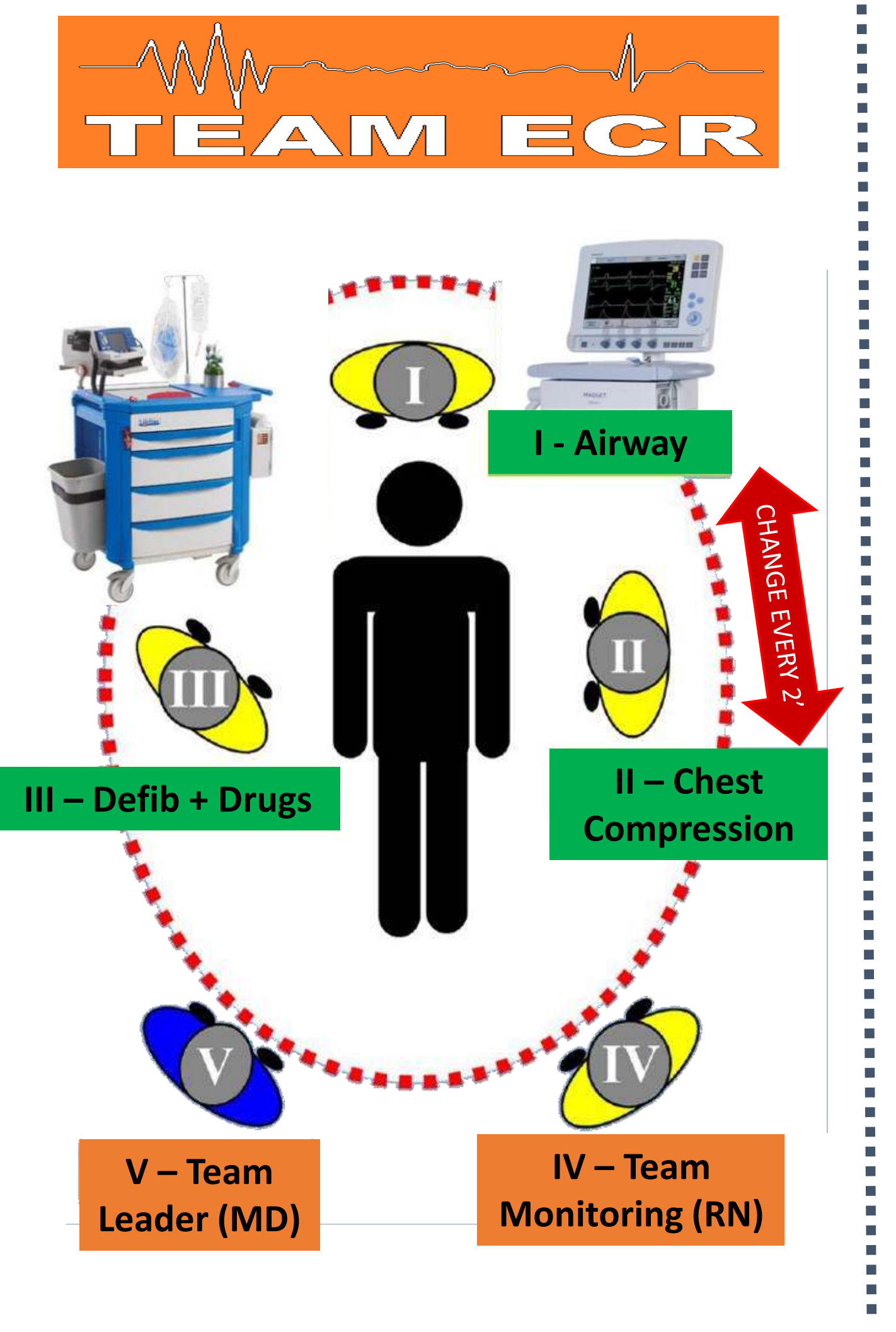

\section{SIMULATIONS AND TEAM PERFORMANCE}

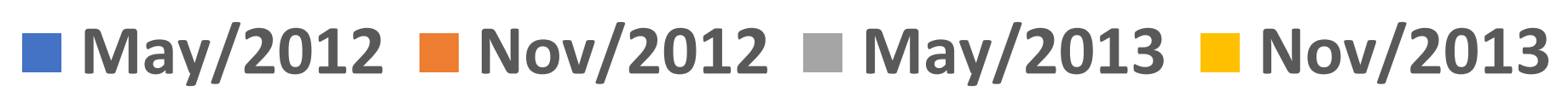

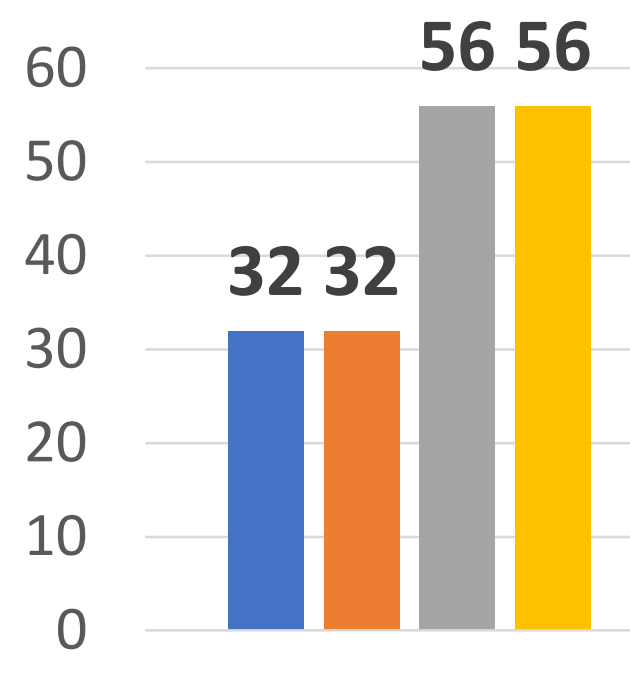

Simulation (n)
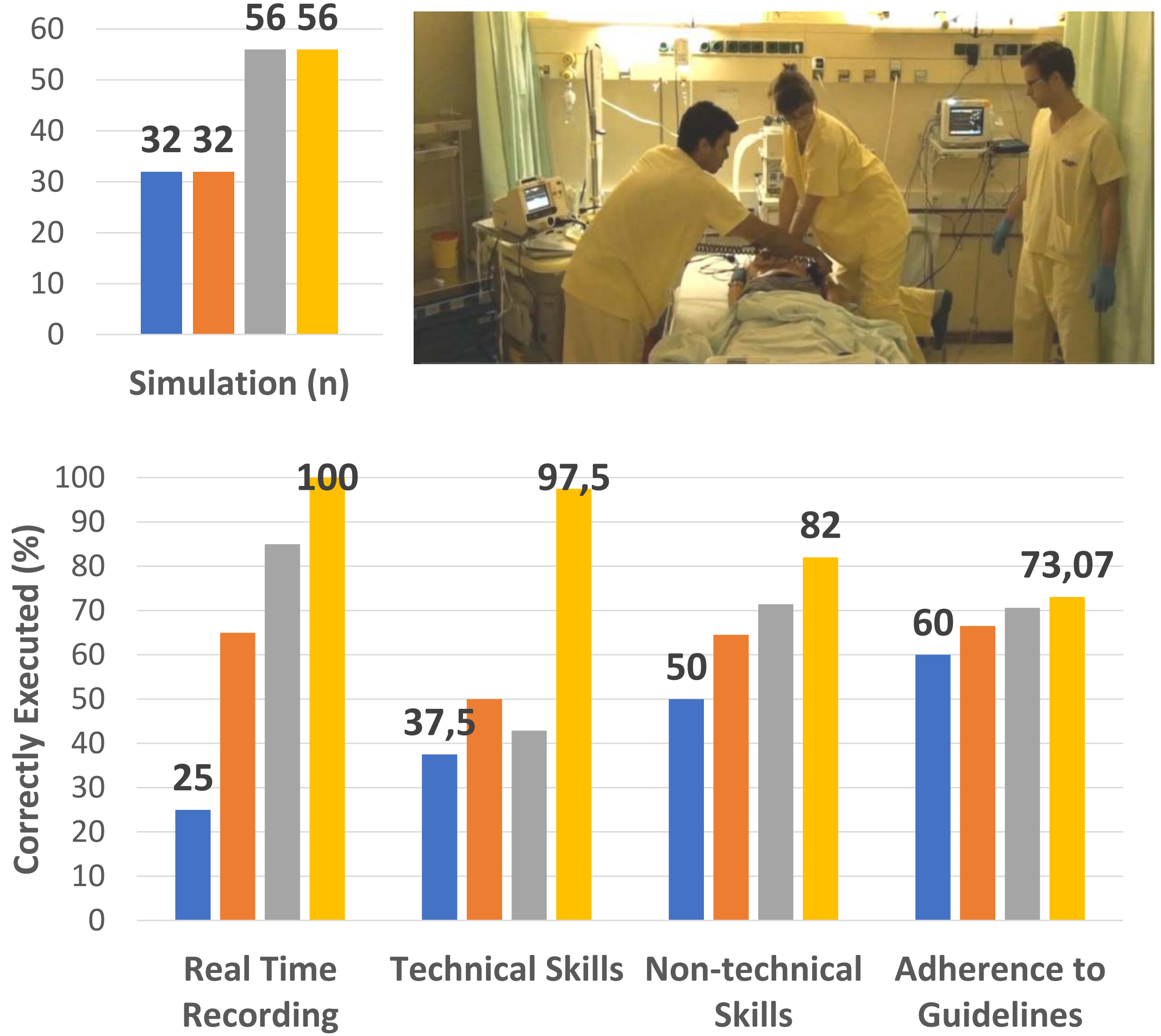
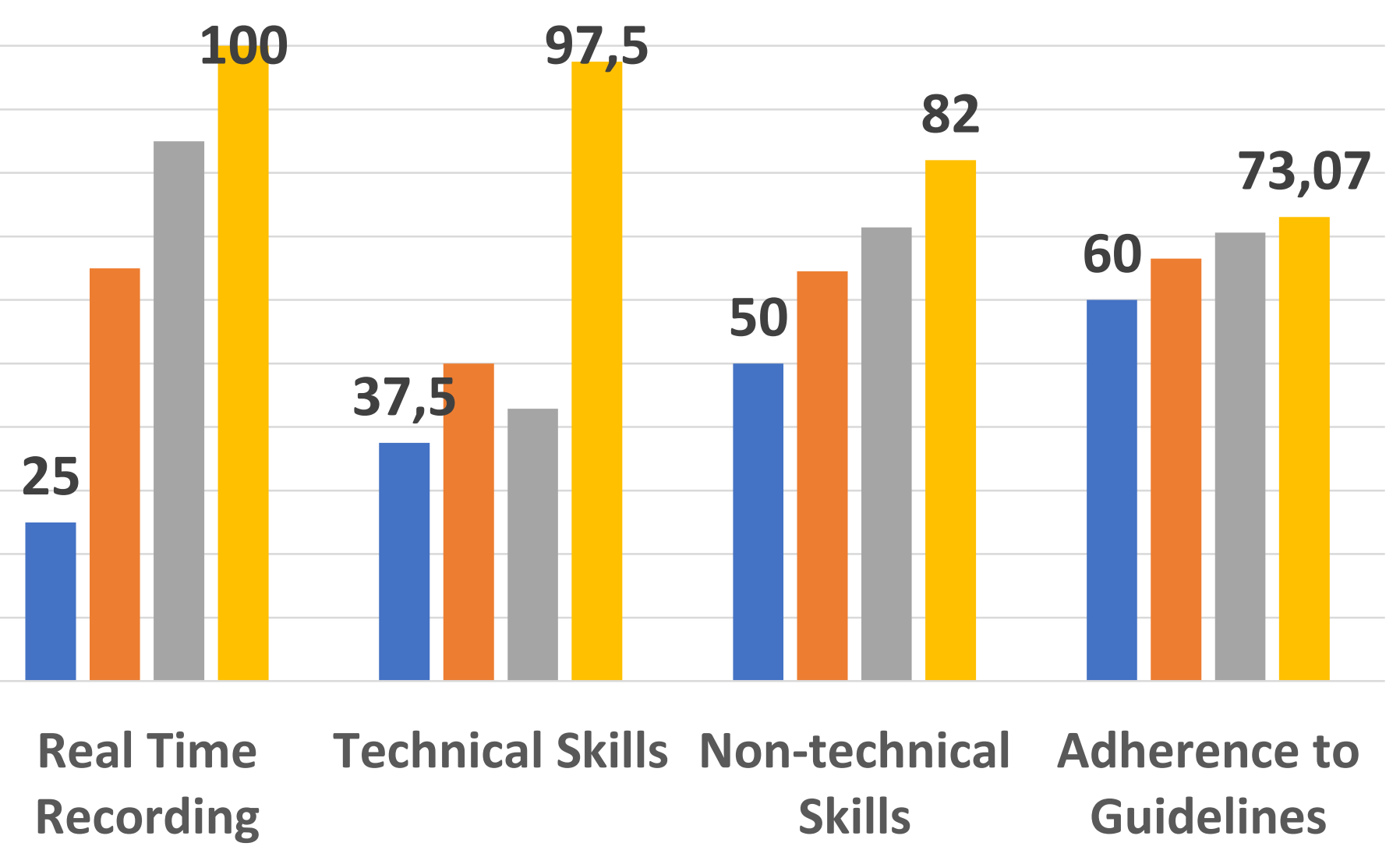

Technical Skills Non-technical Adherence to Skills Guidelines

CONCLUSION: Low-dose high-frequency not certified and immersive team training allow improvement of essential points at IHCA management and to define strategies to reduce time of action, increase coordination and ultimately augment team efficiency. This project is now widespread to all clinical wards since 2014, unfortunately there's no data to relate it to IHCA outcome. 